\title{
An Allergic Risk Factor Analysis of Extraordinary Daytime Only Urinary Frequency in Children
}

\author{
Ling Hou \\ Zhou Zhang \\ Yue Du \\ Xiuli Wang \\ Chengguang Zhao
}

Department of Pediatrics, Shengjing Hospital of China Medical University, Shenyang, I 10004 , People's Republic of China
Correspondence: Yue Du

Department of Pediatrics, Shengjing

Hospital of China Medical University, No.

36 of Sanhao Street, Heping District,

Shenyang, I 10004, People's Republic of

China

Tel +8618940251606

Fax +8602423892617

Email drduyue24@I63.com
Objective: This study aims to investigate the risk factors of extraordinary daytime only urinary frequency (EDOUF) and propose a form of clinical treatment.

Methods: Correlation and binary logistic regression analyses were carried out on the medical records of children with EDOUF, including their history of eczema, urticaria, allergic rhinitis or allergic cough, and pruritus (eye rubbing, etc.).

Results: A total of 266 children with EDOUF, 127 boys and 139 girls, were enrolled in the present study; their average age was $5.60 \pm 2.04$ years. Binary logistic regression analysis revealed that the risk factors of EDOUF in children were eczema (odds ratio $[\mathrm{OR}]=8.393$ ), allergic rhinitis or allergic cough $(\mathrm{OR}=4.459)$, pruritus (eye rubbing, etc.; $\mathrm{OR}=3.879$ ), and elevated total serum $\mathrm{IgE}$ level $(\mathrm{OR}=7.927)$. The efficacy rate of oral administration of antihistamine (desloratadine) was $89.1 \%$.

Conclusion: Systemic or local allergic conditions, such as eczema, allergic rhinitis or allergic cough, and pruritus (including eye rubbing), and elevated total serum IgE level, are risk factors for the occurrence of EDOUF in children. The oral administration of antihistamine (desloratadine) can alleviate the symptoms.

Keywords: extraordinary daytime only urinary frequency, children, allergy, risk factor, loratadine

\section{Introduction}

Children's extraordinary daytime only urinary frequency (EDOUF) (or idiopathic daytime urinary frequency) is a condition in which children urinate frequently (at least once an hour) during the daytime, with reduced urine output each time, no burning sensation or urination pain, almost no incontinence or nocturnal enuresis, and no abnormalities in routine urine test, urine culture, or urinary ultrasound. ${ }^{1,2}$ Before diagnosis, it is necessary to eliminate the frequency of urination associated with psychogenic polydipsia, diabetes mellitus, and nephrogenic diabetes insipidus. ${ }^{3}$ At present, EDOUF accounts for $12.1 \%$ of children who have abnormal urination and is the most common disease presented in pediatric urology clinics. ${ }^{4}$ Children's EDOUF is currently considered to be a benign self-limited disease that is usually spontaneously relieved within three to five months. ${ }^{5}$ Children usually present with normal intelligence and good growth and development. ${ }^{6}$ However, if the symptoms persist all year round, if the frequency of urination is serious (ie, sometimes occurring once every five minutes), or if, as occurs in rare cases, there are nocturia symptoms, the daily lives of the children and their parents are seriously affected. ${ }^{7}$ In order to facilitate intervention to relieve symptoms and shorten the course of the disease, thereby reducing its impact, it is necessary to explore the factors influencing children's EDOUF. 
A diagnosis of children's EDOUF can be confirmed after a medical history is compiled and the results of a physical examination, routine blood and urine tests, and urinary ultrasound examination in the outpatient department are considered. However, attention should be paid to the differential diagnosis of urogenital infection, diabetes mellitus, diabetes insipidus, eosinophilic cystitis, and chronic appendicitis. ${ }^{8}$ Current intervention measures for EDOUF in children include delayed urination training and psychological therapies. ${ }^{4,5}$ The majority of children with EDOUF in the present study also had eczema, urticaria, pruritus (eye rubbing etc.), allergic rhinitis or allergic cough, and a series of systemic or local allergic manifestations, such as elevated total serum IgE level. Some patients were treated with the antihistamine desloratadine and their symptoms were quickly relieved. This prospective study was conducted to analyze the case data of EDOUF in children treated as outpatients at the Pediatric Renal Rheumatology unit of our hospital from June 2018 to June 2019 and the related influencing factors.

\section{Methods}

\section{Study Subjects}

The treatment group in this study comprised children who were diagnosed with EDOUF as outpatients at the Pediatric Renal Rheumatology unit of Shengjing Hospital of China Medical University from June 2018 to June 2019. A control group was formed of children who had physical examinations for trace elements in the Child Health Outpatient Department in the corresponding period. The diagnostic criteria for EDOUF include increased urination frequency (ie, at intervals of a few minutes to an hour) during the day, with reduced urine output each time; no burning sensation or pain during urination; no polydipsia or excessive drinking symptoms; no positive signs found under physical examination; and normal routine urine analysis, urinary ultrasound, and residual urine volume measurement of the bladder. Urinary tract infection, diabetes mellitus, diabetes insipidus, and other organic diseases must be excluded, and no other combined diseases or oral medicine history reported. The inclusion criteria for the treatment group in this study were increased urination frequency (once or more per hour) during the day, with reduced urine volume per time; no burning sensation or pain during urination; almost no urinary incontinence and nocturnal enuresis; and no abnormalities in routine urine analysis, urine culture, and urinary system ultrasound. In addition, where other allergic symptoms were present (or had occurred in the past), the severity of those symptoms was much less than that of frequent urination and did not, therefore, affect daily life.

This study was approved by the Ethics Committee of our center, and the guardians of the children enrolled provided signed informed consent.

\section{Methods}

Data concerning the medical history of children in the control group and the treatment group were collected by questionnaire. This included gender, age, and history of eczema, urticaria, allergic rhinitis or allergic cough, and pruritus (eye rubbing, etc.). Eosinophils were counted and collected according to the routine blood results of a physical examination of each child. Total serum $\operatorname{IgE}$ level was also measured, and waste plasma was collected for testing. Then, a routine urine test was conducted.

Desloratadine dry suspension was orally administered for a course of two weeks to children diagnosed with EDOUF ( $5 \mathrm{mg}$ per dose for children aged $\geq 12$ years, $2.5 \mathrm{mg}$ per dose for children aged $<12$ years and $\geq 6$ years, and $1.25 \mathrm{mg}$ per dose for children aged $<6$ years and $\geq 1$ year) when this was accompanied by eczema, urticaria, allergic rhinitis or allergic cough, pruritus (eye rubbing, etc.), and elevated $\operatorname{IgE}$ (age $\leq 3$ years with $\operatorname{IgE}$ $\geq 20 \mathrm{IU} / \mathrm{mL}$, age $\geq 3$ years and $<6$ years with $\mathrm{IgE} \geq 35 \mathrm{IU} /$ $\mathrm{mL}$, or age $\geq 6$ years and $<20$ years with $\operatorname{IgE} \geq 51 \mathrm{IU} / \mathrm{mL}$ ). Children with EDOUF without the above symptoms were given psychotherapy, and their parents were encouraged to pay them more attention, spend more time with them, and resist scolding them. When a child experiences frequent urination, their attention should be distracted, and appropriate encouragement and rewards should be given if urination frequency improves (ie, urination becomes less frequent). Each child diagnosed with EDOUF in this study (ie, the treatment group) was followed up for two weeks after treatment, and an effective response was defined as a reduction in daytime urination frequency of $50 \%$ or more. $^{5}$

\section{Statistical Methods}

SPSS 18.0 statistical software was used for the statistical analysis, and $P<0.05$ was considered statistically significant. The enumeration data were expressed as mean \pm standard deviation (SD), and the comparison between the two groups was analyzed by one-way analysis of variance (ANOVA). A chi-square test was used for EDOUF; 
however, this may be affected by the single-factor analysis. Binary logistic regression analysis was used for the meaningful correlation analysis of the results of the singlefactor analysis.

\section{Results}

\section{Demographic Data}

The treatment group in the present study comprised a total of 266 children with EDOUF. Their average age was 5.60 \pm 2.04 years, and they included 127 boys $(47.7 \%)$ and 139 girls (52.3\%). The control group comprised 464 children who had physical examinations. Of these children, 215 (46.3\%) were boys and 249 (53.7\%) were girls, and their average age was $5.56 \pm 2.92$ years old. The difference between the two groups in terms of gender composition and age was not statistically significant $(P>0.05)$.

\section{Extraordinary Daytime Only Urinary Frequency-Related Risk Factors \\ Univariate Analysis}

History of eczema, urticaria, allergic rhinitis or allergic cough, and pruritus (eye rubbing etc.), eosinophil count, and total $\operatorname{IgE}$ level were analyzed by univariate analysis. The results, shown in Table 1, indicate that the risk factors of EDOUF in children include a history of eczema, urticaria, allergic rhinitis or allergic cough, or skin pruritus (eye rubbing etc.), and elevated total serum IgE level $(P<0.01)$.

\section{Binary Logistic Regression Analysis}

The significant influencing factors of the above univariate analysis were included in the binary logistic regression model, and the specific evaluation is presented in Table 2 . According to the binary logistic regression analysis (Table 3), the risk factors of EDOUF in children include eczema (odds ratio $[\mathrm{OR}]=8.393$ ), allergic rhinitis or allergic cough $(\mathrm{OR}=4.459)$, pruritus (eye rubbing etc.; $\mathrm{OR}=3.879)$, and elevated total serum IgE level $(\mathrm{OR}=7.927)$.

\section{Therapeutic Effects on Children's Extraordinary Daytime Only Urinary Frequency}

Desloratadine was orally administered to 230 children in the EDOUF group, and 205 of those children presented with improved symptoms at the follow-up two weeks after treatment (an efficacy rate of $89.1 \%$ ). The remaining 36 children in the treatment group did not receive drug therapy because they had no history of eczema, urticaria, allergic rhinitis or allergic cough,
Table I Results of Single Factor Analysis of EDOUF Children

\begin{tabular}{|c|c|c|c|c|}
\hline Group & $\begin{array}{l}\text { EDOUF } \\
\text { Group, } \\
\text { n (\%) }\end{array}$ & $\begin{array}{l}\text { Control } \\
\text { Group, } \\
\text { n (\%) }\end{array}$ & $\begin{array}{l}\text { Pearson's } \\
\chi^{2}\end{array}$ & $P$ \\
\hline $\begin{array}{l}\text { Eczema } \\
\text { Yes } \\
\text { No }\end{array}$ & $\begin{array}{l}160 / 266(60.2) \\
106 / 266(39.8)\end{array}$ & $\begin{array}{l}42 / 464(9.1) \\
422 / 464(90.9)\end{array}$ & 0.550 & 0.000 \\
\hline $\begin{array}{l}\text { Urticaria } \\
\text { Yes } \\
\text { No }\end{array}$ & $\begin{array}{l}29 / 266(10.9) \\
237 / 266(89.1)\end{array}$ & $\begin{array}{l}21 / 464(4.5) \\
443 / 464(95.5)\end{array}$ & 0.121 & 0.001 \\
\hline $\begin{array}{l}\text { Allergic rhinitis or } \\
\text { allergic cough } \\
\text { Yes } \\
\text { No }\end{array}$ & $\begin{array}{l}103 / 266(38.7) \\
163 / 266(61.3)\end{array}$ & $\begin{array}{l}39 / 464(8.4) \\
425 / 464(91.6)\end{array}$ & 0.369 & 0.000 \\
\hline $\begin{array}{l}\text { Pruritus (eye } \\
\text { rubbing etc.) } \\
\text { Yes } \\
\text { No }\end{array}$ & $\begin{array}{l}123 / 266(46.2) \\
143 / 266(53.8)\end{array}$ & $\begin{array}{l}46 / 464(9.9) \\
418 / 464(90.1)\end{array}$ & 0.414 & 0.000 \\
\hline $\begin{array}{l}\text { Eosinophil count } \\
\text { Yes } \\
\text { No }\end{array}$ & $\begin{array}{l}11 / 266(4.1) \\
255 / 266(95.9)\end{array}$ & $\begin{array}{l}18 / 464(3.9) \\
446 / 464(96.1)\end{array}$ & -0.002 & 0.951 \\
\hline $\begin{array}{l}\text { Total lgE level } \\
\text { Yes } \\
\text { No }\end{array}$ & $\begin{array}{l}127 / 266(47.7) \\
139 / 266(52.3)\end{array}$ & $\begin{array}{l}37 / 464(8.0) \\
427 / 464(92.0)\end{array}$ & 0.459 & 0.000 \\
\hline
\end{tabular}

pruritus (eye rubbing, etc.), or increased eosinophil count or elevated total serum IgE level; these children were treated with psychotherapy. At two-week followup, 12 of these children presented with improved symptoms (an efficacy rate of $33.3 \%$ ). Further urodynamics and lumbosacral MRI were recommended for those children who experienced no improvement in symptoms in order to further differentiate and diagnose the cause of the disease.

Table 2 Evaluation Table of Risk Factors of EDOUF Children

\begin{tabular}{|l|l|l|}
\hline Variate & Factors & Evaluation \\
\hline$X 1$ & Eczema & Yes $=$ I, No $=0$ \\
\hline$X 2$ & Urticaria & Yes=I, No=0 \\
\hline$X 3$ & $\begin{array}{l}\text { Allergic rhinitis or allergic } \\
\text { cough }\end{array}$ & Yes=I, No=0 \\
\hline$X 4$ & Pruritus (eye rubbing etc.) & Yes=I, No=0 \\
\hline$X 5$ & Total lgE level & Rise=I, Normal=0 \\
\hline$Y$ & EDOUF & $\begin{array}{l}\text { Occur }=I, \text { Not } \\
\text { Occur }=0\end{array}$ \\
\hline
\end{tabular}


Table 3 EDOUF Children's Risk Factors Binary Logistic Regression

\begin{tabular}{|c|c|c|c|c|c|c|}
\hline \multirow[t]{2}{*}{ Variate } & \multirow[t]{2}{*}{ B } & \multirow[t]{2}{*}{ Wald } & \multirow[t]{2}{*}{ Sig. } & \multirow[t]{2}{*}{$\operatorname{Exp}(B)$} & \multicolumn{2}{|l|}{$95 \% \mathrm{Cl}(\operatorname{Exp}(B))$} \\
\hline & & & & & Lower Limiting Value & Upper Limit Value \\
\hline Eczema & 2.127 & 81.749 & 0.000 & 8.393 & 5.292 & 13.311 \\
\hline Allergic rhinitis or allergic cough & 1.495 & 31.109 & 0.000 & 4.459 & 2.637 & 7.540 \\
\hline Pruritus (eye rubbing etc.) & 1.356 & 29.122 & 0.000 & 3.879 & 2.371 & 6.348 \\
\hline Total IgE level & 2.070 & 62.946 & 0.000 & 7.927 & 4.809 & 13.065 \\
\hline
\end{tabular}

\section{Discussion}

The binary logistic regression analysis in our study revealed that the risk factors of EDOUF in children are eczema $(\mathrm{OR}=8.393)$, allergic rhinitis or allergic cough $(\mathrm{OR}=4.459)$, pruritus (eye rubbing etc.; $\mathrm{OR}=3.879)$, and elevated total serum IgE level (OR = 7.927). The efficacy rate of orally administered antihistamine (desloratadine) was $89.1 \%$.

Extraordinary daytime only urinary frequency is a frequently occurring disease in preschool children, which is consistent with the onset age of $5.60 \pm 2.04$ years in the present study. There is no significant gender difference in the incidence of the disease. The pathophysiological mechanism of EDOUF in children remains unclear. Bergmann et al report that approximately $49 \%$ of affected children may have psychosocial stress or anxiety. ${ }^{1}$ It has been speculated that, as a comprehensive mechanism, emotional stress is connected to the pontine micturition center (Kopressoff's center) through the limbic system (emotional brain), ${ }^{9,10}$ and this may stimulate the desire to micturate, even when the bladder is not full, resulting in the occurrence of EDOUF. Based on this assumption, EDOUF may be spontaneously relieved when emotional stress subsides. It has been reported that 21 of 58 patients with EDOUF had upper respiratory tract diseases, suggesting that upper respiratory tract infection may also induce EDOUF. ${ }^{11,12}$ In another study, $17.4 \%$ of 106 children with EDOUF suffered from constipation. ${ }^{4}$ After the constipation was treated, the symptoms of EDOUF improved. In addition, it has been proven that the occurrence of EDOUF is not correlated with neuropsychiatric diseases, group A streptococcal infection, or pinworm infection. ${ }^{1}$ At present, it remains unclear whether other causes, such as an inflammatory process and metabolic or genetic factors after infection, are correlated to EDOUF. Therefore, further research is required. It has been speculated that EDOUF may be caused by unrecognized or unknown irritants that stimulate the bladder or urethra.
In a study conducted on 178 children with asthma, Soyer et al found that $47.1 \%$ of those under six years of age had a higher risk of frequent urination. ${ }^{13}$ In the present prospective study, conducted as a follow-up to our previous study, logistic regression analysis confirmed that the risk factors of EDOUF include eczema, allergic rhinitis or allergic cough, pruritus (eye rubbing, etc.), and elevated total serum IgE level. This indicates that systemic and local allergic conditions play an important role in inducing EDOUF in children. Oral antihistamines were given to children in this study who had one or more of the following conditions: eczema, urticaria, allergic rhinitis or allergic cough, pruritus (eye rubbing, etc.), and elevated total serum IgE level. Although $89.1 \%$ of those patients presented with improved symptoms after two weeks, the lack of a corresponding control group means that this result is not sufficient to explain the therapeutic effect of oral antihistamines. However, the fact that the symptoms of children with EDOUF were relieved after taking antihistamines indicates that there is a certain correlation between the occurrence of EDOUF and allergic factors.

The clinical manifestations of EDOUF and overactive bladder syndrome are similar. The main clinical manifestations of the latter are urgency and frequency of urination and nocturia, with or without the urge of urinary incontinence. Of patients aged 20 to 39 with bladder hypersensitivity syndrome and interstitial cystitis whose lower urinary tract symptoms are more prominent, approximately $80 \%$ have allergies (of a variety of types, including allergic asthma, pollen or food allergy, or skin allergy), ${ }^{14}$ while an increase in specific $\operatorname{IgE}$ is correlated to the pathogenesis of interstitial cystitis. ${ }^{15}$ In summary, from previous research, combined with the results of the present study, it can be assumed that EDOUF, overactive bladder syndrome, and interstitial cystitis are all correlated to allergies. The mucosae of the bladder and urethra display symptoms of allergic reactions similar to those of the skin and intestinal mucosae. Hence, allergy-sensitive subjects may 
experience lower urinary tract symptoms, such as increased frequency of urination. Whereas children with mild symptoms can recover through self-regulation, other children may develop more serious symptoms that affect their daily lives, including their schooling. Therefore, it has been speculated that the above three disorders may involve a gradual progression from the perspective of allergies. The symptoms of EDOUF are usually simultaneously relieved within days, weeks, or months, with an average remission time of approximately three to five months. ${ }^{5}$

The limitations of the present study include the fact that the discussion on the risk factors of EDOUF in children was confined to allergic diseases. Related mental and psychological factors, constipation and intestinal problems, and seasonal factors were not included in the present study. The control group was not involved in the evaluation of the efficacy of antihistamines; such an investigation could either better explain the therapeutic effect of the drug or further confirm that allergy is a risk factor of EDOUF. Similarly, while psychotherapy and delayed-urination training methods exist for the treatment of EDOUF, it is difficult to comprehensively evaluate their efficacy due to the lack of a corresponding control group, ${ }^{4,5}$ as in the present study. Therefore, more research is needed to establish the role of psychotherapy.

\section{Conclusion}

The present study reveals that eczema, allergic rhinitis or allergic cough, pruritus (eye rubbing, etc.), and elevated total serum IgE level are risk factors of EDOUF in children. The oral administration of antihistamines can relieve symptoms. Clinicians should pay more attention to these conditions in the course of diagnosis and treatment and offer correct guidance to children with EDOUF and their parents in order to provide better prevention and treatment.

\section{Ethics Approval and Consent to Participate}

This study was conducted in accordance with the declaration of Helsinki.This study was conducted with approval from the Ethics Committee of Shengjing Hospital of China Medical University. A written informed consent was obtained from all participants.

\section{Consent for Publication}

Consent for publication was obtained from every individual whose data are included in this manuscript.

\section{Funding}

There is no funding to report.

\section{Disclosure}

All authors have contributed significantly to the manuscript and declare that the work is original and has not been submitted or published elsewhere. None of the authors have any financial disclosure or conflicts of interest.

\section{References}

1. Bergmann M, Corigliano T, Ataia I, et al. Childhood extraordinary daytime urinary frequency-a case series and a systematic literature review. Pediatr Nephrol. 2009;24(4):789-795. doi:10.1007/s00467-008-1082-9

2. Corigliano T, Renella R, Robbiani A, Riavis M, Bianchetti MG. Isolated extraordinary daytime urinary frequency of childhood: a case series of 26 children in Switzerland. Acta Paediatr. 2007;96 (9):1347-1349. doi:10.1111/j.1651-2227.2007.00406.x

3. Austin PF, Bauer SB, Bower W, et al. The standardization of terminology of lower urinary tract function in children and adolescents: update report from the standardization committee of the international children's continence society. J Urol. 2014;191(6):1863-1865.e13. doi:10.1016/j.juro.2014.01.110

4. Marzuillo P, Diplomatico M, Marotta R, et al. Extraordinary daytime only urinary frequency in childhood: prevalence, diagnosis, and management. $J$ Pediatr Urol. 2018;14(2):177.e1-177.e6. doi:10.1016/j.jpurol.2017.12.005

5. Fuentes M, Magalhães J, Barroso U Jr. Diagnosis and management of bladder dysfunction in neurologically normal children. Front Pediatr. 2019;7:298. doi:10.3389/fped.2019.00298

6. Hellerstein S, Linebarger JS. Voiding dysfunction in pediatric patients. Clin Pediatr (Phila). 2003;42(1):43-49. doi:10.1177/ 000992280304200107

7. Cohen HA, Nussinovitch M, Kauschansky A, et al. Extraordinary daytime urinary frequency in children. $J$ Fam Pract. 1993;37(1):28-29.

8. Stephens FD, Whitaker J, Hewstone AS. True, false and sham urinary tract infections in children. Med J Aust. 1966;2(18):840-842. doi:10.5694/j.1326-5377.1966.tb97554.x

9. Bass LW. Pollakiuria, extraordinary daytime urinary frequency: experience in a pediatric practice. Pediatrics. 1991;87(5):735-737.

10. Griffiths D. Neural control of micturition in humans: a working model. Nat Rev Urol. 2015;12(12):695-705. doi:10.1038/nrurol.2015.266

11. Walker J, Rickwood AM. Daytime urinary frequency in children. BMJ. 1988;297(6646):455. doi:10.1136/bmj.297.6646.455

12. Robson WL, Leung AK. Extraordinary urinary frequency syndrome. Urology. 1993;42(3):321-324. doi:10.1016/0090-4295(93)90624-J

13. Soyer OU, Kilincoglu B, Senyucel MF, et al. Dysfunctional voiding in children with asthma. Arch Dis Child. 2013;98(4):312-314. doi:10.1136/archdischild-2012-301867

14. Yamada T. Significance of complications of allergic diseases in young patients with interstitial cystitis. Int J Urol. 2003;10(Suppl): S56-8. doi:10.1046/j.1442-2042.10.s1.12.x

15. Homma Y, Ueda $\mathrm{T}$, Tomoe $\mathrm{H}$, et al.; Interstitial cystitis guideline committee. Clinical guidelines for interstitial cystitis and hypersensitive bladder syndrome. Int J Urol. 2009;16(7):597-615. 


\section{Publish your work in this journal}

Risk Management and Healthcare Policy is an international, peerreviewed, open access journal focusing on all aspects of public health, policy, and preventative measures to promote good health and improve morbidity and mortality in the population. The journal welcomes submitted papers covering original research, basic science, clinical \& epidemiological studies, reviews and evaluations, guidelines, expert opinion and commentary, case reports and extended reports. The manuscript management system is completely online and includes a very quick and fair peer-review system, which is all easy to use. Visit http://www.dovepress.com/testimonials.php to read real quotes from published authors. 